Business \& Economics | Tripat Gill

\section{Uncomfortable ethics for autonomous vehicles}

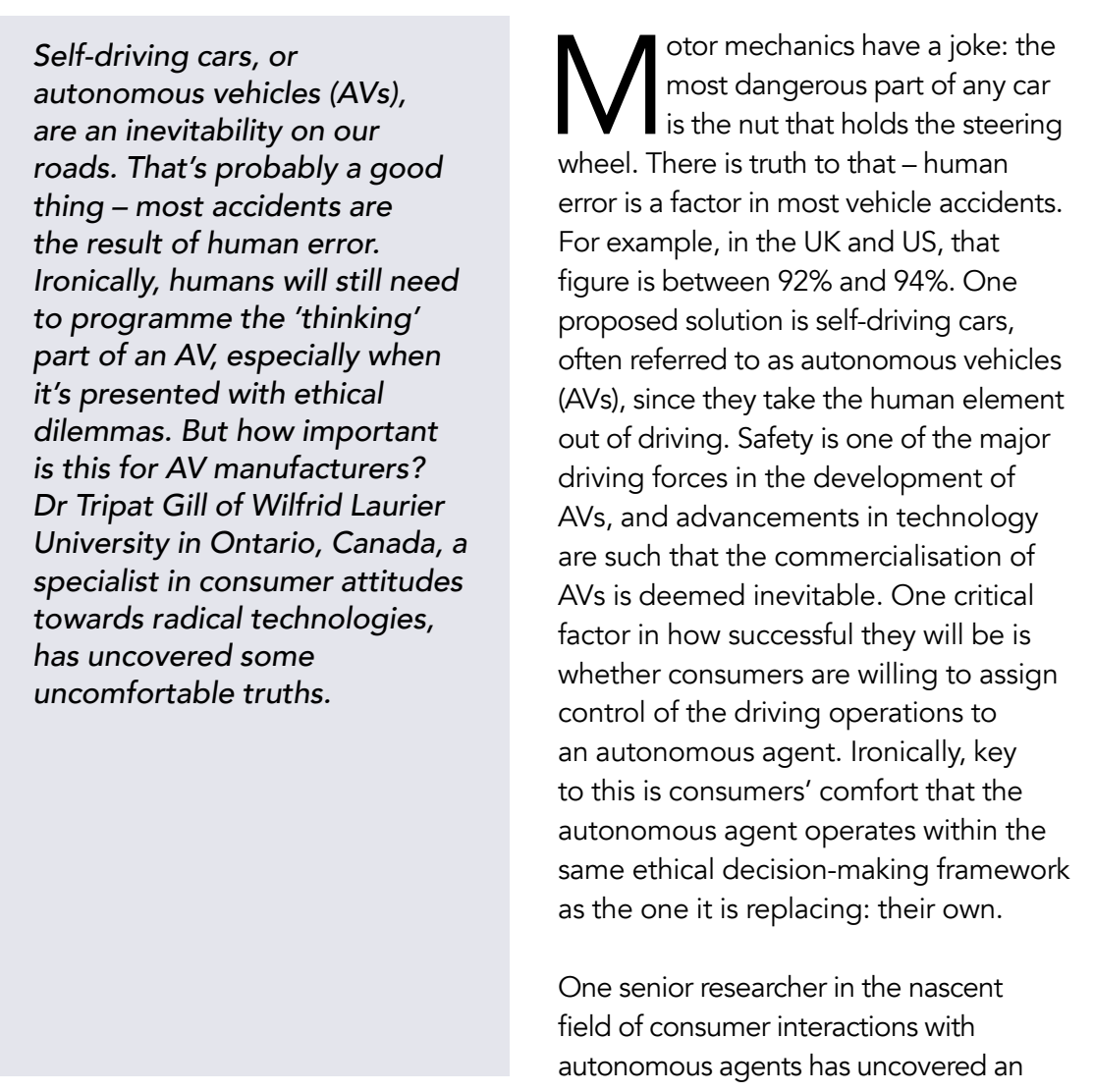

uncomfortable truth about this and just who will one day get inside an AV. Dr Tripat Gill is an associate professor of marketing at Wilfrid Laurier University Ontario, Canada, and a specialist in what factors encounage the adoption of technological innovations, especially and artificial intelligence (A). Of particul interest to Gill are the social imparts of such technologies and the ethical challenges they pose. This is particularly the case for AVs: not only must an AV negotiate the myriad physical challenges of road travel, but it must also be able to make difficult ethical decisions. For this reason, parallel to research in AV spatial negotiating technology, significant esearch within both computer sciences and social sciences is going into what moral norms should be 'built into' the A component of an AV. A common theme to this research is the 'ethical dilemm

\section{THE ETHICAL DILEMMA}

Research in this area typically presents tre dilemma thus. If a pedestrian steps in

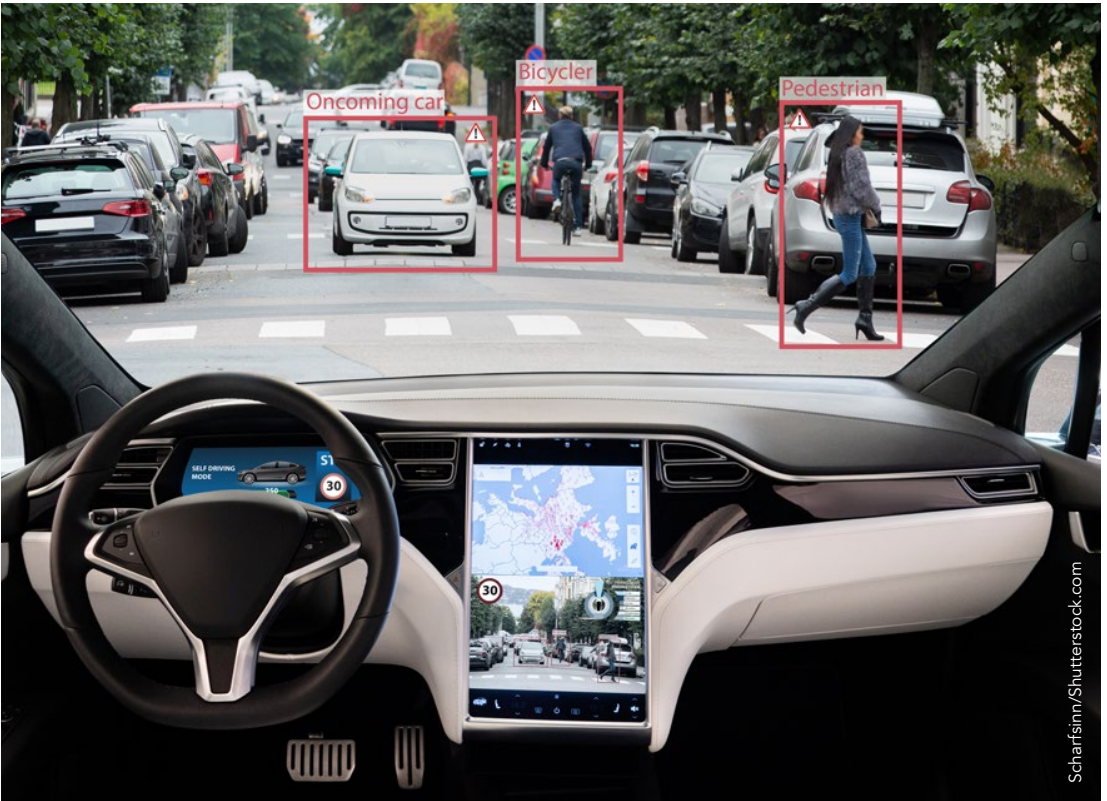

in time, but and he vehicle cannot sto of two people, does it hit the one person? What if that person is a child and the other two are adults? Should that make a difference? Most studies have examined utilitarian dilemmas such as sacrificing one life for two or choosing between harm tudies have focused on a less-researche dilemma: one target of potentially serious injury is sitting in the car.

In a study published in 2020, Gill presented respondents with a 'stay or swerve' scenario to determine what they and what they thought an AV shoulc they wer a paugenger in should do ft they were a passenger in the AV. Using scenario as such. a pedestrian steps in font of the vehicle, if the vehicle stays on course, it will hil the pedestrian, probably harm: swening will put the vehicte a collision course with a tree or pole. probably killing or seriously iniuring the respondent - as the driver in the regular car or passenger in the AV.

A key outcome of this study was that while most participants selected 'swerve' as the preferred course of the vehicle, they were far more likely to choose to stay on course and harm the pedestrian if they were a passenger in the $A V$ than if they were driving themselves. When Gill repeated the study but adjusted it to make the car significantly more expensive, he outcone was the same. Even replacing the simple diagram wi physical harm by getting respondents to immerse their arm in freezing water had little effect on the outcome. Whil most participants still chose 'swerve' and avoid harm to the pedestrian - the odds of choosing 'stay' and harm the pedestrian were nearly two-fold higher a passenger in the $A V$ than if they were behind the wheel of a typical vehicle.

Gill explains this as follows: when we drive a car, we have control over our actions and hence feel responsible for the consequences of our decisions. Even though self-harm violates the fundamental evolutionary instinct of self-preservation, we stil have a moral intuition not to harm others. However, as passengers in an AV, we would have lower therefore can attribute the responsibility for any harmful consequences to the AV. Factors that could magnify or mitigate this phenomenon would be whether we own the vehicle (and therefore it should somehow be programmed as part of our self-identity), if it's rented or a taxi (and thus more 'distanced'), or whether we see the AV in a 'servant' context (and therefore duty-bound to protect us).

\section{ATTRIBUTING}

RESPONSIBILITY TO A VEHICLE This responsibility attribution should wory AV designers and manufacturers if they believe building a moral code into the vehicles is essential. However, according to Gil, many manufaction din

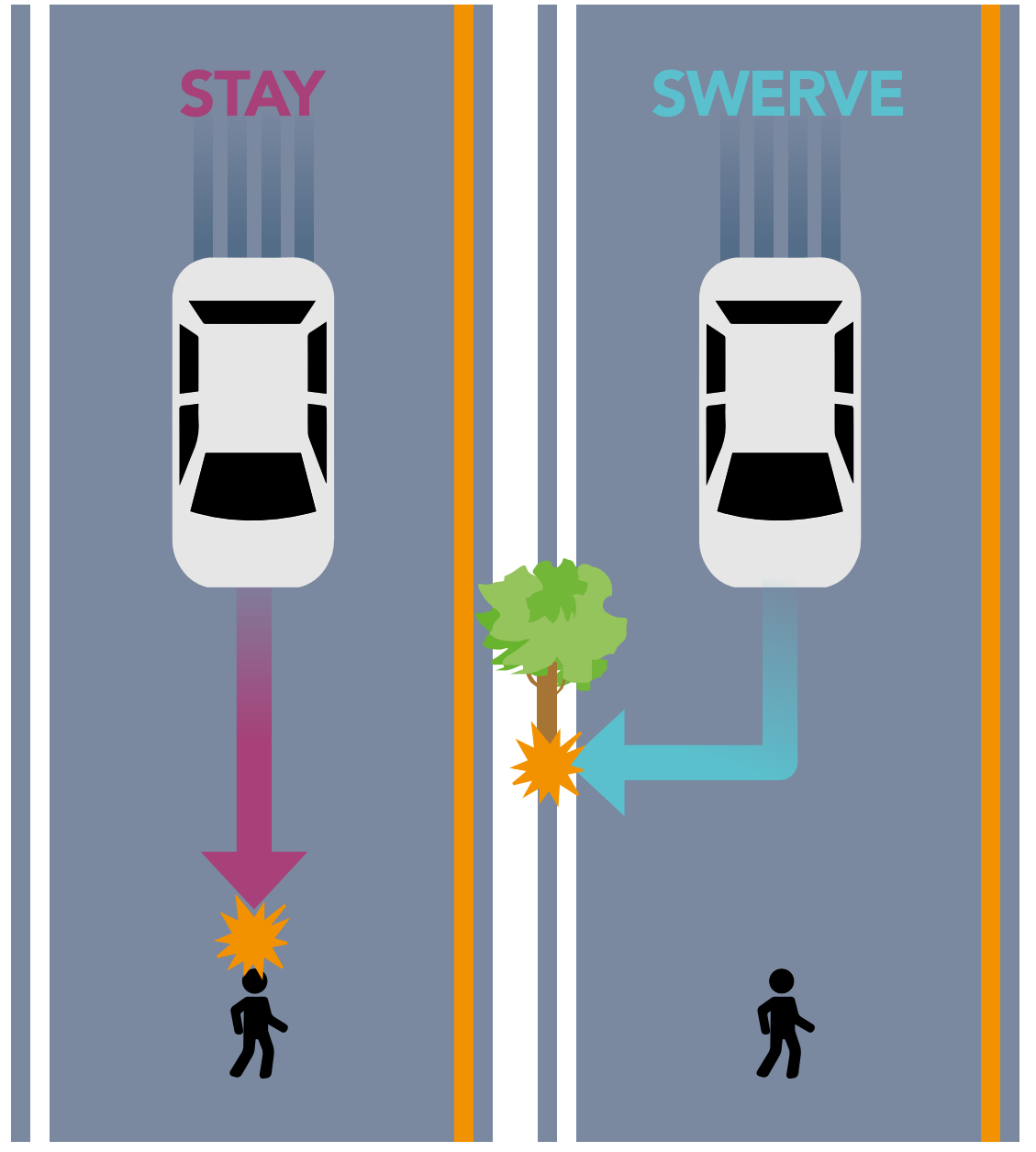

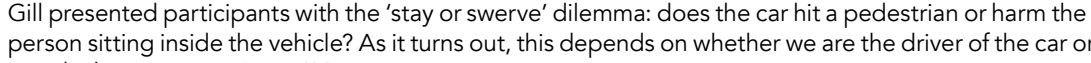

as a distraction. Instead, they consider inclement wers a comprehension test to ensure they and accurately reading rnising objects, understood the survey topic, they were more pressing issues. But do consumers benefits. These included reduced

Gill's recent studies have focused on a less-researched dilemma - where one target of potentially serious harm is sitting in the car.

agree? After all, they're the ones who will - or will not - buy the vehicles.

accidents, freeing up commuting time, To test this, Gill conducted two surveys as part of a study published in 2021. The surveys had a total of 1,678 US-based respondents in the typical target marke as early adopters of AV technology. They were presented with detailed information about $A V s^{\prime}$ benefits and the different technical, legal, and ethical
challenges in the design and adoption increased mobility for the elderly and disabled, reduced traffic congestion, health costs. They were then asked to ate the importance of overcoming the challenges should they consider being a passenger in an AV. Among the ethical challenges was the focal ethical dilemma AV should seriously harm a pedestrio or thould seriously harm a pedestrian 


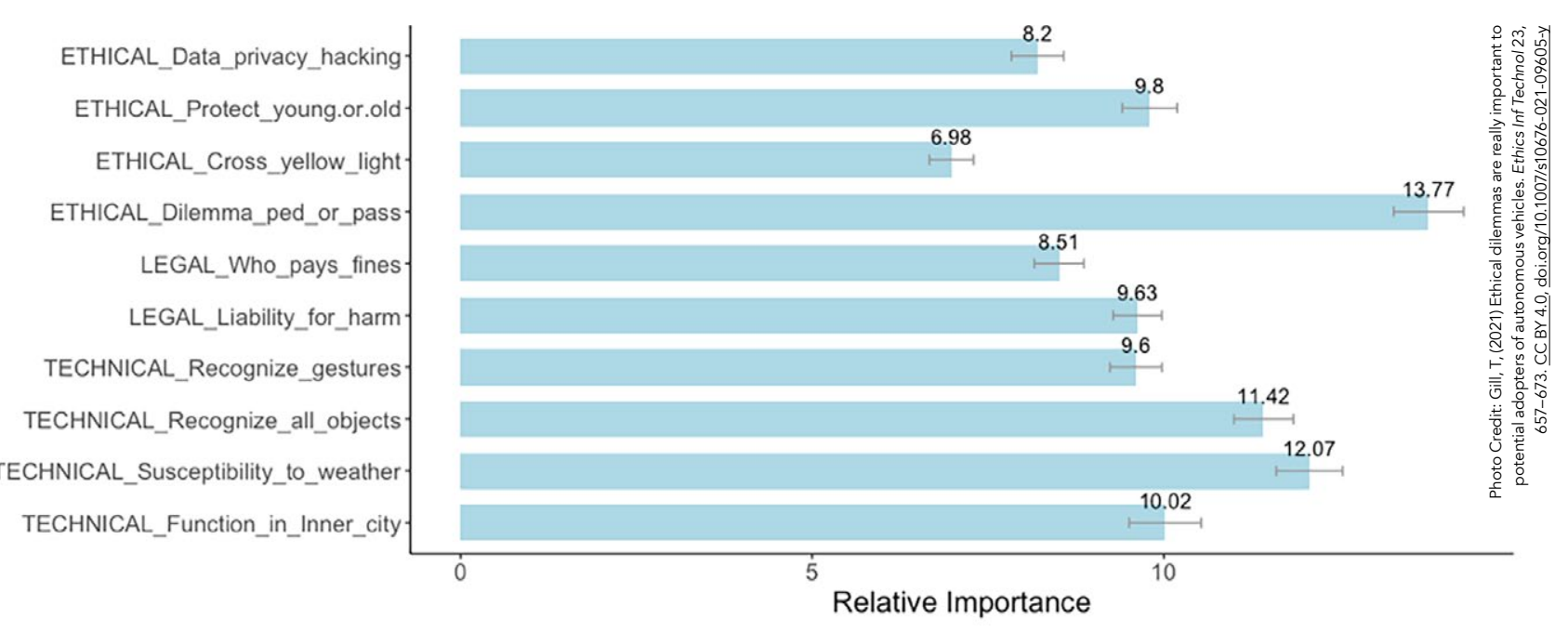

Relative importance of the challenges in the design and operation of AVs. Participants $(N=1,006)$ were asked to allocate 100 points among the 10 listed
ethical, legal, and technical issues based on their perceived importance to overcome these challenges for adoption of $A V$ s.

asked to rate the relative importance of overcoming the different challenges by challenges (four four ethical, including the focal dilemma).

The safety benefits of $A V$ s scored the highest rating. Among the technical challenges, recognising objects, gestures, and road signs and operating

in inclement weather were rated the most important to overcome. The important gal wallong Among the ethical challenges, the most important was the focal dilemm a whether an AV should seriously harm a pedestrian or its passenger. Notably, respondents considered the ethical dilemma as the most significant challenge to overcom

Notably, respondents considered the ethical dilemma as the most significant challenge to overcome in whether they would consider adopting an AV, more so than any of the technical or legal challenges.

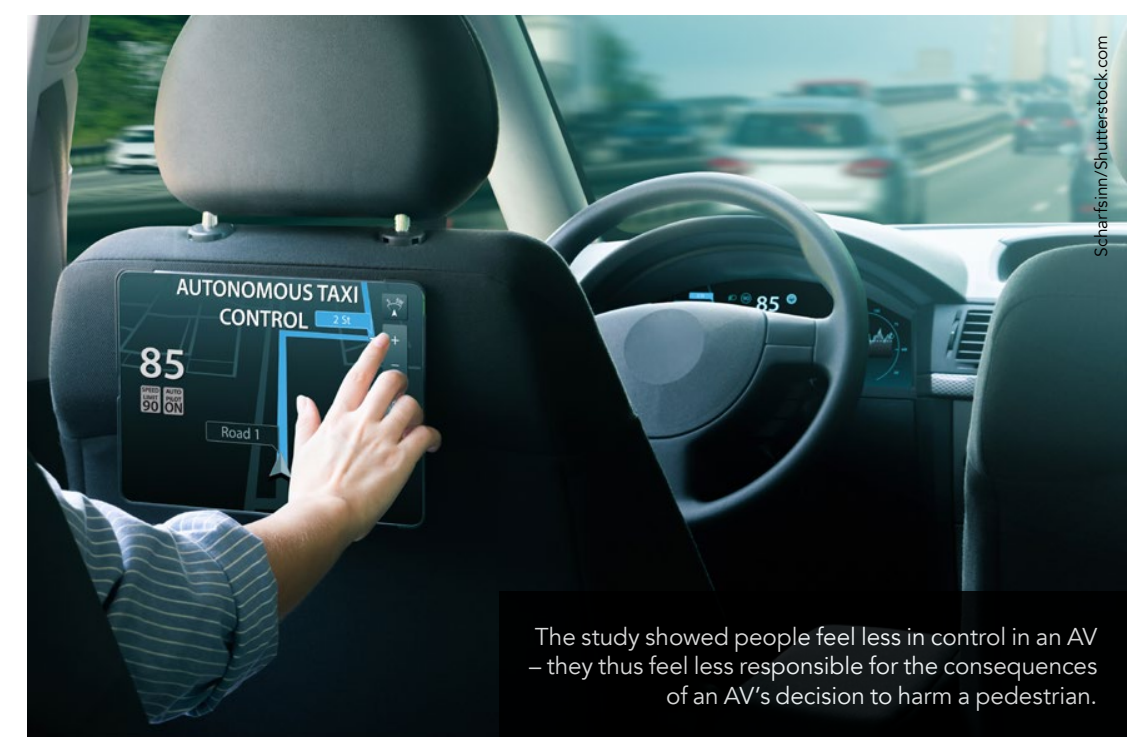

In whether they would consider adopting an hypothesised.

\section{THE ONE HUMAN ELEMENT}

When, in 2018, an Uber autonomous test a pedestrian walking a bicycle across a road in Tempe, Arizona, Uber suspended its AV programme, despite the US National Transportation Safety Board (NTSB) finding that human error was mostly to blame for the crash. Uber knew the accident had fed a primary fear of AVs: will they be able to detect and avoid another human and brake in time? And if not, would the AV's emergency avoidance actions put their passengers' lives in danger? While continual testing and advances in AV technology are whittling chay the remaining technological the inevitability of AVs on our roads, the ethical calculus governing AVs is stillforemost in the minds of consumers.

As Gill's research has shown, among the myriad benefits offered by autonomous vehicles, safer road use ranks the highest among those who would consider getting into one. Indeed, taking the human factor out of vehicle use is one way to reduce road fatalities. However, there is one human' element that potential users seem to want in an AVIf they were sitting inside: sensitivity to the ethical dilemma around harming either a pedestrian or themselves should the scenario arise, no matter how rare that may be and how

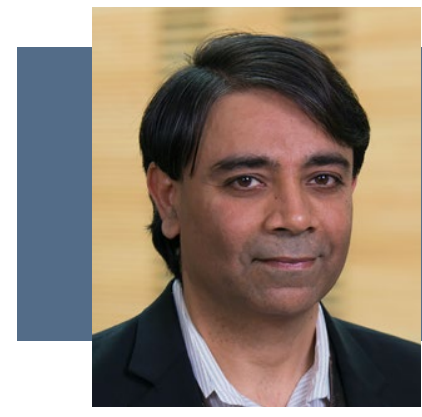

\section{Behind the Research}

\section{Dr Tripat Gill}

E: tgill@wlu.ca T: +15198840710 (ext 4042) W: tripatgill.ca \@ @GillTripat

\section{Research Objectives}

Dr Gill examines ethical dilemmas in the context of autonomous vehicles and how artificial intelligence can promote self-interest.

\section{Detail}

Address

Lazaridis School of Business, Wilfrid Laurier University Avenue, 75 University Avenue West, Waterloo, ON Canada, N2L3C5

Dr Tripat Gill is an associate professor of marketing at the Lazaridis School of Business and Economics, Wilfrid Laur University in Waterloo, Ontario, Canada. He received a PhD from McGill University in Montreal, Canada, and has previously held positions in marketing at Ontario Tech University in Oshawa, Ontario, and at Case Western Reserve University in Cleveland, Ohio, in the US. His research examines the factors encouraging consumers to adopt technological innovations and the social and ethical artificial intelligence.

Funding

S Canada (SSHRC) www.sshrc-crsh.gc.ca/home-accueileng.aspx

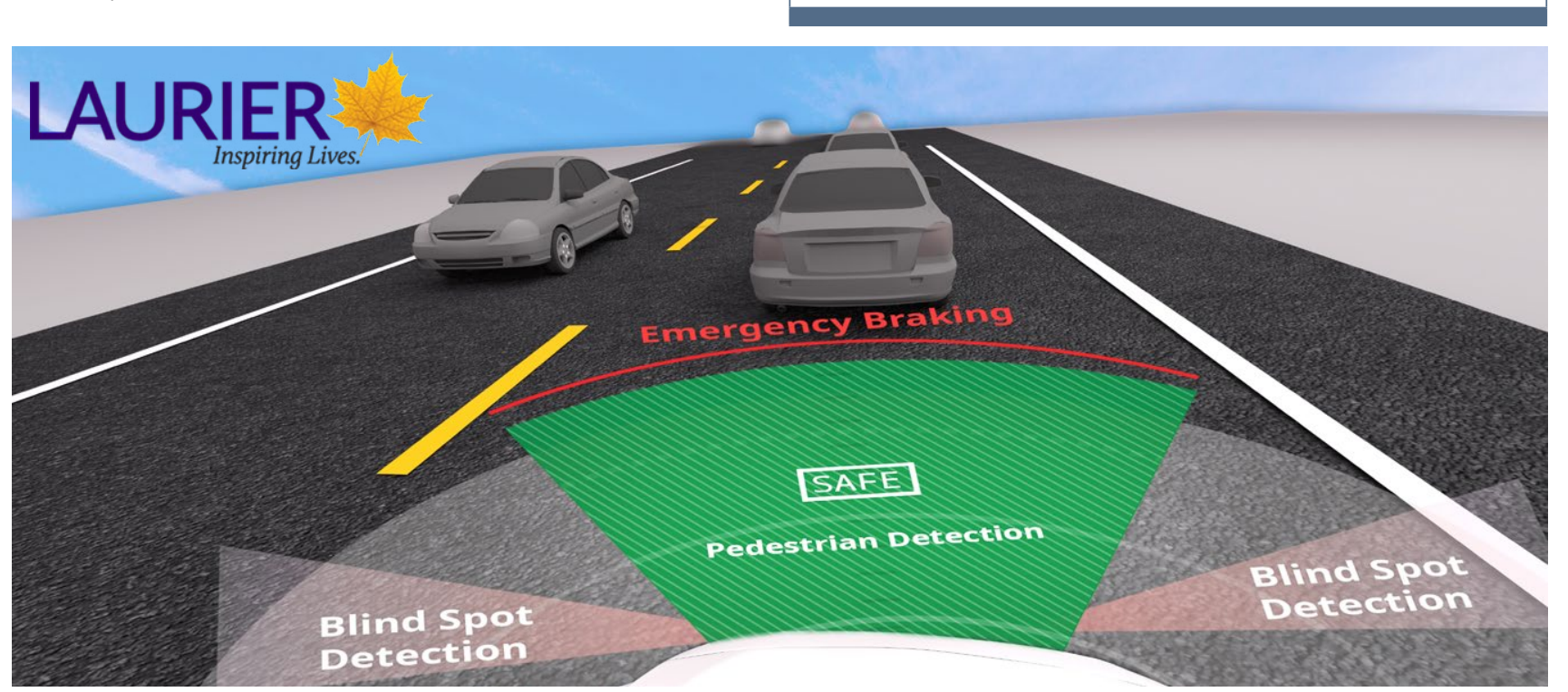

\section{References}

Gill, T, (2021) Ethical dilemmas are really important to potential adopters of autonomous vehicles. Ethics and Information $09605-y$

Gill, T, (2020) Blame It on the Self-Driving Car: How Autonomous Vehicles Can Alter Consumer Morality. Journal of Consumer Research, 47(2), 272-291. doi.org/10.1093/jcr/ ucaa018

Personal Response

Given what your research has shown, how do you think $A V$ manufacturers should react?

II I think that AV manufacturers cannot disregard the issue of ethical dilemmas. My research shows that people passengers vs. pedestrians) as the most significant challenge in their adoption of AVs. While people are cognisant of the technical issues facing AVs (such as recognising signage and operating in bad weather), they are most concerned about the potential risk that ethical dilemmas can pose. However rare, people do want to know how AVs will address these dilemmas. How much weight will they put on the lives of passengers versus the people outside? Whatever solution is proposed, it needs buy-in from the public, or else they wil not adopt and he promise of AVs saving lives will remain unfulfilled. II 